\title{
Contribuições das Câmaras Setoriais e Temáticas à Formulação de Políticas Públicas e Privadas para o Agronegócio ${ }^{(1)}$
}

\author{
MINISTÉRIO DAAGRICULTURA, PECUÁRIAEABASTECIMENTO
}

\section{APRESENTAÇÃo}

O recente desempenho surpreendente do agronegócio brasileiro é resultado da disponibilidade de terras agricultáveis, mecanizáveis e de baixo custo, de gente empreendedora, (pequenos, médios e grandes produtores rurais) e da disponibilidade de tecnologia tropical. Além da tecnologia biológica que multiplica o potencial da terra e da tecnologia mecânica que potencializa a capacidade da mão-de-obra, a tecnologia organizacional disponibiliza informações de mercado para a tomada de decisões dos agricultores e incentiva uma interação harmoniosa entre os diferentes elos das cadeias produtivas.

A harmonização dos interesses entre os agentes de uma determinada cadeia produtiva engloba o estabelecimento de prioridades de ação, questões relativas a suprimento de produtos ou insumos em quantidade e qualidade estabelecidos e acordo de preços que remunerem todos os agentes, incentivando-os a permanecerem na atividade. Não se configuram somente interesses privados de lucro das empresas, mas também interesse público de garantia de suprimento dos bens e serviços e crescimento sustentado da cadeia, no médiolongo prazos, com aumento da renda e do emprego e seus efeitos colaterais no resto da economia.

Para alcançar tais resultados, o setor público conta com a forte atuação das cadeias produtivas do agronegócio, organizadas em Câmaras Setoriais e Temáticas. Essa parceria resulta no apoio à formulação de políticas públicas setoriais e no debate de temas, orientados para o aumento da eficiência econômica nos processos produtivos.

A interlocução com a sociedade, uma das prioridades estratégicas do Ministério da Agricultura, Pecuária e Abastecimento - MAPA, procura estabelecer diálogo e organizar suas demandas, dando maior visibilidade e efetividade às políticas públicas, valorizando o agronegócio e seus componentes perante a sociedade. Esse diálogo se dá por meio da atuação de 30 Câmaras Setoriais e Temáticas, atualmente instaladas, reunidas sob a coordenação do Conselho do Agronegócio e do Conselho Nacional de Política Agrícola, e apoiadas por uma unidade na estrutura organizacional específica do MAPA.
A formulação de políticas, a sua negociação e implementação, exigem do MAPA uma gestão efetiva. A recente reforma administrativa foi o primeiro passo na modernização e aparelhamento, embora todas as atividades sejam importantes, algumas merecem prioridade por sua importância e por apresentarem necessidade constante de aprimoramento. É neste contesto que o Ministério ganha papel de destaque ao deter informações e estudos estratégicos sobre o agronegócio. Numa visão de longo prazo, o MAPA se transforma no grande instrumento de apoio ao setor produtivo.

Ao construir o documento com as Contribuições das Câmaras Setoriais e Temáticas à Formulação de Políticas Públicas e Privadas para o Agronegócio, o MAPA se projeta para o futuro quanto às principais tendências de setores e temas do agronegócio, com o objetivo de fornecer subsídios aos formuladores de políticas públicas, para a tomada de decisão e para o delineamento de linhas de atuação, embasando e fortalecendo os instrumentos de política agrícola, visando o desenvolvimento sustentável do agronegócio brasileiro.

\section{Luis Carlos Guedes Pinto}

Ministro de Estado da Agricultura, Pecuária e Abastecimento

\section{Documento Básico das Câmaras Setoriais e Temáticas}

\section{As Câmaras}

As Câmaras Setoriais e Temáticas são foros de interlocução criados pelo Ministério da Agricultura, Pecuária e Abastecimento - MAPA para a identificação de oportunidades ao desenvolvimento das cadeias produtivas, definindo ações prioritárias de interesse para o agronegócio brasileiro e seu relacionamento com os mercados interno e externo. Este elo entre governo e setor privado resulta em um mecanismo democrático e transparente de participação da sociedade na formulação de políticas públicas.

As Câmaras Setoriais - relacionadas à idéia de agrupamento de segmentos da cadeia produtiva; e Temáticas - relacionadas com serviços, temas ou áreas

\footnotetext{
${ }^{1}$ Reprodução autorizada de documento divulgado pela internet em dezembro de 2006
} 
de conhecimento e atuação no agronegócio - têm seus princípios fundamentados em seis conceitos básicos: eqüidade no tratamento entre os diferentes elos das cadeias produtivas, qualidade nos serviços, garantia da segurança alimentar, competitividade, harmonização entre os setores e paridade público e privado na sua co-gestão.

Constituídas por representantes de entidades de caráter nacional, representativas de produtores, trabalhadores, consumidores, empresários, autoridades do setor privado e representantes de órgãos públicos, parlamentares, técnicos governamentais e instituições bancárias, as Câmaras atendem às exigências de um setor em franco crescimento e que é responsável por uma parcela representativa da economia nacional - 27,9\% do Produto Interno Bruto, 36\% das exportações e 37\% dos empregos - 18 milhões de postos no campo. Seus integrantes discutem e propõem soluções que se refletem em diferentes ramos do setor desde a matéria-prima, necessária à produção, até a logística de distribuição, armazenamento, comercialização e exportação.

\section{As 30 Câmaras do MAPA}

Existem 30 Câmaras que representam diferentes setores e temas do agronegócio nacional. As Câmaras Setoriais abrangem as Cadeias Produtivas do Leite e Derivados; Carne Bovina; Aves e Suínos; Caprinos e Ovinos; Eqüideocultura; Mel e Produtos Apícolas; Fruticultura; Citricultura; Hortaliças; Flores e Plantas Ornamentais; Oleaginosas e Biodiesel; Açúcar e Álcool; Cachaça; Fumo; Viticultura, Vinhos e Derivados; Algodão e Derivados; Borracha Natural; Cacau e Sistemas Florestais Renováveis; Arroz; Feijão; Mandioca; Milho e Sorgo; Culturas de Inverno e Agricultura Orgânica. As Câmaras Temáticas abrangem Infra-estrutura e Logística do Agronegócio; Insumos Agropecuários; Agricultura Competitiva e Sustentável; Financiamento e Seguro do Agronegócio; Negociações Agrícolas Internacionais; Ciências Agrárias.

As Câmaras Setoriais e Temáticas atuam como estrutura de apoio ao Conselho Nacional de Política Agrícola e ao Conselho do Agronegócio. Esses organismos contribuem com análises e informações sobre a conjuntura econômica e social do país, na identificação de prioridades definidas em planos da macroeconomia, definição de preços mínimos, elaboração de plano de safras, busca de consenso para conflitos e negociações internas e externas, assim como na definição dos índices de produtividade da terra.

\section{A Coordenação-Geral de Apoio às Câmaras Setoriais e Temáticas-CGAC}

A CGAC foi criada pelo Decreto $n^{\circ} 5.351$, de 21 de janeiro de 2005, com os principais objetivos de dotar o MAPA de estrutura adequada para receber, encaminhar e dar respostas às proposições das Câmaras Setoriais e Temáticas e estimular as Câmaras a priorizar a discussão de questões estruturais da cadeia produtiva, colaborando para a formação de políticas de longo prazo.

Tem como missão: articular as ações entre as Câmaras Setoriais e Temáticas e o Governo, tendo em vista atender às demandas do agronegócio em benefício da sociedade.

Sua visão é ser instrumento de referência na articulação entre os diferentes segmentos envolvidos nos arranjos produtivos do agronegócio e o governo, capaz de responder com eficácia aos desafios da sociedade.

Como diretrizes; manter as Câmaras atuantes e cumprindo sua missão, motivando a participação da sociedade nas Câmaras e incentivando a criação de Câmaras que tenham relevância para o agronegócio. Além disso, procura estimular a qualidade da informação oriunda das Câmaras e dar suporte logístico às reuniões das Câmaras.

Dentre suas atribuições destacam-se:

- Coordenar os processos de gestão do suporte técnicooperacional necessário ao funcionamento dos órgãos colegiados e de suas Câmaras.

- Apoiar a manutenção do relacionamento do setor agropecuário com as entidades e órgãos vinculados, estabelecidos pelas referidas Câmaras.

- Apoiar o encaminhamento das demandas apresentadas pelas Câmaras, observadas as interfaces com os assuntos da área de competência do Ministério ou demais áreas da administração pública.

- Apoiar o intercâmbio e o fluxo de informações entre as Câmaras e os setores público e privado do agronegócio.

- Interagir com as Secretarias do MAPA, para articulação das propostas apresentadas pelas Câmaras em relação à especificação e elaboração de instrumentos e mecanismos técnicos, econômicos e financeiros para o agronegócio.

Câmara Setorial da Cadeia Produtiva de Flores e Plantas Ornamentais

\section{Histórico \\ Saulo Gonzales ${ }^{2}$}

A Câmara Setorial da Cadeia Produtiva de Flores e Plantas Ornamentais foi instalada em 16 de dezembro de 2003 no Auditório do Ministério da Agricultura, Pecuária e Abastecimento, em Brasília, DF, reunindo de modo fiel e participativo associações de viveiristas, produtores, exportadores, varejistas, órgãos públicos e outras entidades privadas relacionadas ao setor.

O Ministro interino da Agricultura, Pecuária e Abastecimento, José Amaury Dimarzio abriu os trabalhos da Câmara indicando como Presidente o representante do

\footnotetext{
(2) Chefe de Divisão da CGAC/SE/MAPA e Supervisor da Câmara Setorial da Cadeia Produtiva de Flores e Plantas Ornamentais do Conselho do Agronegócio.
} 
setor privado, Renato Opitz, e, como Secretária Executiva, a representante do setor público, Maria Mazzarello, nomes que foram referendados por ocasião da primeira reunião ordinária da Câmara. Os perfis destes espelham a organização, o nível técnico e a importância econômico e social do setor. O Presidente Renato Opitz é engenheiro agrônomo, pós-graduado pela FEA/USP e vem atuando como Presidente da Câmara Setorial de Flores e Plantas Ornamentais do Estado de São Paulo desde 2001. É DiretorGeral da empresa Promoções \& Eventos RBB, organizadora dos eventos Hortitec, Enflor e Garden Fair, desde 2002.

Foi Gerente de Produto da Cooperativa Agro Pecuária Holambra de 1990 a 1997 e Diretor Geral da Cooperativa Veiling Holambra de 1997 a 2001. A Secretária Executiva Maria Mazzarelo é engenheira agrônoma e possui mais de 20 anos de experiência no Ministério da Agricultura, Pecuária e Abastecimento, na Secretaria de Desenvolvimento Agropecuário e Cooperativismo, nas áreas de produção, certificação de sementes e mudas, defesa fitossanitária, coordenação de laboratório vegetal e negociações internacionais no agronegócio.

A Câmara foi criada pela Portaria/MAPA n ${ }^{0}$ 26, publicada no Diário Oficial da União, de 19 de janeiro de 2006 e posteriormente alterada pela Portaria $n^{\circ} 120$, de 15 de maio de 2006. Em suas reuniões, têm sido identificadas as principais demandas do setor e encaminhadas ao Ministério da Agricultura, Pecuária e Abastecimento para esclarecimentos e providências cabíveis pelas áreas técnicas, bem como o Presidente da Câmara e outros integrantes do setor têm sido recebidos diretamente pelo Ministro.

O Presidente enfatiza a importância da instalação da Câmara para melhor articular os trâmites público-privado, tais como: desembaraço nas exportações, redução de tributos incidentes sobre o setor, registro e proteção de cultivares, e, elaboração e fiscalização da legislação fitossanitária.

Enfim, a organização do setor de modo que todos os segmentos da cadeia fortaleçam-se tornando a cadeia competitivas e sustentável, encontrou forte apoio no mecanismo de trabalho da Câmara.

\section{Apresentação}

As lideranças especialmente indicadas como representantes da floricultura brasileira nos âmbitos nacional, regionais e estaduais dos diversos pólos brasileiros de produção, reunidos e congregados pelo Congresso FIAFLORA EXPOGARDEN de Floricultura / Brasília 2005, realizado em Brasília, Distrito Federal, nos dias 26 e 27 de maio de 2005, elaboraram o presente documento, ora publicamente divulgado como as Diretrizes da Câmara Setorial da Cadeia Produtiva de Flores e Plantas Ornamentais.

Esta Agenda representa um documento síntese das discussões e propostas surgidas ao longo dos dois dias de trabalho do Congresso, bem como das contribuições agregadas de diversas lideranças previamente consultadas e está destinada a constituir-se numa agenda de trabalho, comprometimento mútuo e envolvimento cooperativo e convergente entre técnicos, profissionais, produtores, empresas e instituições públicas e privadas objetivando o desenvolvimento permanente e o crescimento ambiental e economicamente sustentado e socialmente includente da floricultura brasileira do futuro.

\section{Renato Opitz Presidente da Câmara}

\section{Introdução}

Este documento representa uma síntese das discussões e propostas surgidas ao longo dos dois dias de trabalho do Congresso FIAFLORA EXPOGARDEN de Floricultura / Brasília 2005, bem como das contribuições agregadas de diversas lideranças previamente consultadas e está destinada a constituir-se numa agenda de trabalho, comprometimento mútuo e envolvimento cooperativo e convergente entre técnicos, profissionais, produtores, empresas e instituições públicas e privadas objetivando o desenvolvimento permanente e o crescimento ambiental e economicamente sustentado e socialmente includente da floricultura brasileira do futuro.

\section{Ambiente Externo e Interno}

No Brasil, ainda que com uma profissionalização e dinamismo comercial relativamente recente, a atividade contabiliza números extremamente significativos. Já são formalmente reconhecidos mais de 4 mil produtores, cultivando uma área de cerca de 5,2 mil hectares anualmente, em 304 municípios brasileiros. No entanto, estudos setoriais conduzidos recentemente em diversos Estados vêm sinalizando para o fato de que, na realidade, tais números devem estar grandemente subestimados.

Uma nova consolidação de informações é, hoje, objetivo de estudo por parte dos principais órgãos de representação setorial.

Embora ainda fortemente concentrada no Estado de São Paulo, particularmente nas regiões dos municípios de Atibaia e Holambra, a floricultura brasileira evidencia fortes tendências de descentralização produtiva e comercial por várias regiões de todo o país. Atualmente, assiste-se ao notável crescimento e consolidação de importantes pólos florícolas no Rio Grande do Sul, Paraná, Santa Catarina, Minas Gerais, Rio de Janeiro, Espírito Santo, Goiás, Distrito Federal, Tocantins, Amazonas, Mato Grosso, Pará, Alagoas, Ceará, Pernambuco, Sergipe, Paraíba, Bahia e Maranhão.

Em termos globais, estima-se que a atividade responda pela geração de mais de 120 mil empregos, dos quais 58 mil (48,3\%) estão localizados na produção; 4 mil (3,3\%) na distribuição; 51 mil (42,5\%) no comércio varejistas e 7 mil (5,9\%) em outras funções, principalmente nos segmentos de apoio.

A produção de flores e plantas ornamentais propicia rendimentos entre $\mathrm{R} \$ 50 \mathrm{mil}$ a $\mathrm{R} \$ 100 \mathrm{mil}$ por hectare, gerando, na média nacional, 3,8 empregos diretos por hectare, que vêm a equivaler a 14,2 empregos numa propriedade dedicada à floricultura. 
Ressalte-se, ainda, que 94,4\% desses empregos são preenchidos com mão-de-obra permanente, essencialmente contratados $(81,3 \%)$, enquanto que o trabalho familiar responde por $18,7 \%$ do total empregado, caracterizando-se, assim, o seu inquestionável papel e importância socioeconômica.

A produção é desenvolvida em pequenas propriedades, cuja média nacional de área cultivada é de 3,5 hectares. Existem diferenças regionais importantes. Assim, o estado de Goiás, por exemplo, possui uma área média de cultivo - a maior nacional - de 6,3 hectares, o que se explica pelo fato da sua vocação para a produção de mudas de plantas ornamentais, exigentes em maiores dimensões físicas de área.

No Brasil, a distribuição da área cultivada com flores e plantas é de 50,4\% para mudas; 13,2\% para flores envasadas; $28,8 \%$ para flores de corte; 3,1\% para folhagens em vasos; 2,6\% para folhagens de corte e 1,9\% para outros produtos da floricultura.

No mercado interno, avalia-se que a floricultura brasileira movimente, anualmente, um valor global entre US\$ 750 milhões e US\$ 800 milhões. O consumo doméstico gira em torno de US\$ 4,70 per capita, valor esse, que já experimentou notável crescimento no período de 1994 a 1998, quando somou US\$ 6,00 per capita. Contudo, tais números são, ainda, muito baixos frente a padrões mundiais. Na Suíça e na Noruega, por exemplo, o consumo per capita chega a US\$170,00 e US\$143,00, respectivamente. NaAlemanha, US\$137,00, nos EUA, US\$ 36,00 e na Argentina, US\$25,00.

As estimativas indicam que o consumo potencial é, pelo menos, equivalente ao dobro do atual, se superadas as restrições geradas por aspectos econômicos e culturais, entre os quais o da concentração da demanda apenas em datas festivas e comemorativas, como o dia das mães, dos namorados, finados, entre outros.

Os principais mercados atacadistas estão concentrados no Estado de São Paulo, envolvendo cerca de 800 agentes e movimentando, anualmente, perto de R\$ 356 milhões. Ressalte-se que alguns desses mercados incorporam as mais modernas técnicas de comercialização, tais como o sistema de leilões próprios do modelo "Veiling Holandês” e a comercialização eletrônica de mercadorias, destacando-se de todo o restante da horticultura comercial no Brasil. A distribuição varejista de flores e plantas ornamentais no Brasil conta com cerca de 18 mil pontos de venda. O Estado de São Paulo representa cerca de 40\% de todo o consumo nacional, enquanto que apenas a cidade de São Paulo absorve perto de $25 \%$ de toda a demanda dessas mercadorias.

Em termos de faturamento, as flores em vaso representam 50\% da movimentação na Cadeia, as flores de corte, $40 \%$ e as plantas verdes, $10 \%$ (não incluem as palmeiras, árvores e arbustos para paisagismo).

No comércio internacional, a participação das exportações no valor global da floricultura brasileira é avaliada em cerca de 3\%, com resultados crescentes e vigorosos ao longo dos últimos anos.

Rompendo o ciclo de performance inconstante verificado ao longo dos anos 1990, o setor tem conseguido alavancar significativamente seus resultados no comércio internacional, com valores acrescidos em $113 \%$ no período dos quatro primeiros anos de implantação e execução do Programa Setorial Integrado de Exportações de Flores e Plantas Ornamentais do Brasil e que significaram vendas globais próximas de US\$23,5 milhões, em 2004.

A profissionalização do segmento exportador vem se intensificando nos últimos anos e, hoje, o país já se projeta neste cenário como importante referencial de qualidade e competitividade. Os investimentos realizados na Cadeia Produtiva estão atingindo maturidade e seus efeitos já se fazem sentir com maiores velocidade e intensidade. A abertura de novos mercados, o aumento da eficiência e competitividade e o fechamento contínuo de novos negócios permitem projetar que as exportações, em 2005, atingirão resultados próximos de US\$ 31 milhões, o que representará incremento de mais de $30 \%$ sobre os resultados do ano anterior.

O mercado mundial de flores e plantas ornamentais é avaliado em 75 bilhões de euros anuais, sendo que, deste total, 60 bilhões de euros advêm do setor de flores e plantas, 14 bilhões do mercado de mudas e o restante da produção e circulação de bulbos.

Por sua vez, o fluxo no comércio internacional é avaliado como sendo da ordem de US\$ 9 bilhões anualmente, hoje concentrado em países como a Holanda, Colômbia, Itália, Dinamarca, Bélgica, Quênia, Zimbábue, Costa Rica, Equador, Austrália, Malásia, Tailândia, Israel, EUA(Havaí) e outros.

A participação nacional é de apenas $0,22 \%$ no fluxo internacional dessas mercadorias. Contudo, o potencial do país permite um crescimento para cerca de 1,5\%, nos próximos anos.

A participação brasileira é concentrada principalmente na exportação de mudas de flores e plantas ornamentais (48,46\% do total, com notável destaque para crisântemos), bulbos (23,08\%), além de rosas, flores tropicais como orquídeas, bromélias, abacaxis ornamentais, zingiberáceas e outros itens. As folhagens brasileiras também têm muito boa e crescente aceitação no mercado internacional.

A Holanda, principal cliente internacional da floricultura brasileira, concentra suas aquisições nos seguintes grupos de produtos: Mudas de Outras Plantas Ornamentais, principalmente de crisântemos (44,29\%), Bulbos em repouso vegetativo (40,09\%), Flores Frescas (12,42\%) e Folhagens Secas (3,20\%).

Para os EUA, a preferência de importações fica com as Flores Frescas, principalmente rosas, com 56,82\% das aquisições. Mudas de Outras Plantas Ornamentais ficam com 22,44\%, Folhagens Secas, com 10,51\%, Bulbos (9,64\%) e Mudas de Orquídeas (0,58\%).

A Itália, terceiro maior comprador em importância econômica, concentra suas compras também em Mudas de Outras Plantas Ornamentais, com 84,57\% de sua pauta. Seguem-lhe as Folhagens Secas (9,92\%) e as Folhagens Frescas (2,52\%).

Atualmente, os mercados prioritários para o crescimento das exportações do Brasil são: Alemanha, Holanda, Estados Unidos da América, Itália, França, Inglaterra, Japão e Argentina. Também é evidente o crescente interesse dos mercados dos países ibéricos 
(Portugal e Espanha) pelos produtos brasileiros, notadamente para flores e folhagens tropicais. Como mercados opcionais, em fase de prospecção, encontramse a Rússia e os Emirados Árabes.

As extraordinárias condições de produção do país, dotado de diversidade de solo e clima, permitem o cultivo de um infinito número de espécies de comprovada qualidade e beleza e conferem ao produto brasileiro como flores tropicais, crisântemos, orquídeas, bromélias, gerânios, abacaxis ornamentais, entre outros, condições de abrir espaços e firmar-se competitivamente no mercado mundial.

A transformação das potencialidades em oportunidades efetivas de negócios tem se tornado uma realidade, na medida em que produtores e exportadores rompem importantes pontos de estrangulamento ao longo da cadeia produtiva. Isto tem sido possível graças à adoção de um elenco de medidas e ações apontadas, orientadas e coordenadas por órgãos, instituições, empresas e programas de apoio, fomento e promoção, como o FloraBrasilis - programa resultante de Convênio de cooperação técnica entre o Instituto Brasileiro de Floricultura - Ibraflor e a Agência Brasileira de Promoção de Exportações e Investimentos - APEX-Brasil, SEBRAE Nacional, Câmara Setorial Nacional da Cadeia Produtiva de Flores e Plantas Ornamentais, entre outros.

O fortalecimento do comércio exterior da floricultura brasileira, sob todos os aspectos, é uma ação absolutamente vital para a garantia de um grande número de empregos, tanto no meio rural, quanto nas cidades e, mesmo, para a sobrevivência de inúmeras propriedades e empresas agrícolas.

Constitui-se, desta forma, numa alternativa eficiente e eficaz para o desenvolvimento econômico e social, nos âmbitos nacional e macro-regionais, bem como para o enfrentamento do êxodo rural, evitando a caótica migração para as metrópoles e o crescimento do desemprego, da fome e da violência urbana.

Neste sentido, levando-se em consideração o estímulo exportador, e as potencialidades produtivas do país, que lhe conferem possibilidades de inserção competitiva no mercado mundial, estima-se que as exportações evoluirão de forma expressiva, a partir do patamar atual, alcançando cerca de US\$ 80 milhões/ano em 2007.

Todo esse esforço exportador deverá elevar a área de produção destinada à de exportação, para cerca de 1.500 ha, contribuindo com a geração de 15.000 novos postos de trabalho, com mão-de-obra qualificada e capacitados para o desempenho efetivo de suas atividades.

\section{Contribuições para a Formulação de Políticas Públicas e Privadas}

A partir das discussões, debates e sugestões das lideranças e da Plenária do Congresso FIAFLORA EXPOGARDEN de Floricultura / Brasília 2005 e, com o objetivo de identificar e encaminhar as mais adequadas propostas e soluções para os atuais entraves e gargalos ocorrentes ao longo da Cadeia Produtiva de Flores e Plantas Ornamentais do Brasil organizou-se a presente
Agenda com as Diretrizes para Formular Políticas, segundo o envolvimento sugerido para os principais agentes, instituições, empresas e organismos públicos e privados com atuação direta ou em importantes interfaces com a floricultura profissional em todo o país.

\section{Apoio, Fomento e Promoção do Crescimento e Desenvolvimento do Mercado Interno.}

- Incentivar, apoiar e promover o crescimento e o desenvolvimento do mercado interno de consumo para as flores e plantas ornamentais, considerando a extrema relevância, no caso brasileiro, das suas dimensões, características e potencialidades, de modo a agregar as vantagens competitivas em relação à imensa maioria dos fornecedores internacionais, como os países produtores da América Central e África e que se constitui na existência simultânea e sinérgica de um potente mercado doméstico e de imensas potencialidades no comércio internacional. Diretriz de Longo Prazo;

- Aumentar a oferta de produtos de elevada qualidade, durabilidade e competitivade para o mercado interno, melhorando, de maneira global, as condições de operação, rentabilidade, acessibilidade e modernização do mercado, garantindo melhores níveis de remuneração de produtores, comerciantes e distribuidores e da satisfação dos clientes e consumidores. Diretriz de Médio Prazo;

- Viabilizar a adoção generalizada de melhores práticas de conservação pós-colheita, padronização, classificação, embalagem, apresentação, circulação das flores e plantas ornamentais, bem como a da implementação de melhores e mais adequadas infra-estruturas logísticas de distribuição e conservação dessas mercadorias. Diretriz de Médio Prazo;

- Incentivar, fomentar e promover a adoção generalizada da padronização e classificação de produtos, embalagens e processos baseadas nos melhores resultados, tendências e expectativas do mercado internacional, viabilizando, a criação e a consolidação de uma cultura da qualidade no país e de uma cultura exportadora. Diretriz de Médio Prazo;

- Incentivar, fomentar e promover a diversificação e diferenciação dos hábitos regionais de consumo de flores e plantas ornamentais, favorecendo as vocações, preferências e habilidades geográficas, ecológicas, culturais e socioeconômicas das populações e reduzindo a atual centralização da produção, do fluxo e do reduzido número de espécies difundidas massivamente para todo o país. Diretriz de Longo Prazo;

- Incentivar, promover e participar de campanhas institucionais e educativas permanentes que informem o consumidor sobre características, origens, usos e cuidados com as flores e plantas ornamentais, que incentivem e impulsionem novas compras, que diminuam o efeito sazonal no comércio e que estimulem a entrada de novos segmentos consumidores no mercado, como os públicos masculinos, o jovem e o infantil. Diretriz de Médio Prazo;

- Organizar e disponibilizar sistemas de monitoramento da evolução e mudanças do comportamento do consumidor e dos principais mercados internacional, nacional e locais, 
através da realização de pesquisas de campo diretas e de fontes secundárias permanentes de informação, de modo a promover adaptações e ajustes necessários, fidelizando a clientela e identificando novas oportunidades de negócios. Diretriz de Curto Prazo.

\section{Coordenação e Governança da Cadeia Produtiva de Flores e Plantas Ornamentais do Brasil}

- Buscar a permanente estruturação orgânica e funcional da Cadeia Produtiva, por meio do fortalecimento dos seus principais fóruns e órgãos nacional, regionais e estaduais, como a Câmara Setorial Nacional e suas congêneres de âmbitos estaduais, o Instituto Brasileiro de Floricultura, Sociedades e Associações de segmentos e áreas componentes, especialmente de produtores e suas cooperativas, profissionais do paisagismo, do comércio e distribuição atacadista e varejista, de proteção de cultivares, entre outros, visando a consolidação da prática da discussão sistemática e da deliberação conjunta sobre as melhores soluções e encaminhamentos das demandas e expectativas setoriais, em um ambiente de mútua cooperação entre as esferas pública e privada da economia nacional. Diretriz de Longo Prazo;

- Estimular o debate amplo, franco e aberto entre as partes componentes da Cadeia, bem como a construção formal ou informal de Códigos de Conduta e de Relacionamentos entre as Partes, de modo a favorecer a consolidação de alianças estratégicas, promover a especialização, o ganho de eficiência e competitividade no atendimento ao cliente final, maior harmonia e redução das assimetrias nos relacionamentos e um melhor fluxo das informações sobre as reais condições e expectativas do mercado ao longo de toda a Cadeia Produtiva. Diretriz de Longo Prazo;

- Viabilizar sistemas de captação e produção sistemática e periódica de estatísticas e indicadores sobre a evolução de todos os segmentos da Cadeia Produtiva, especialmente a partir da realização de censos abrangentes e confiáveis sobre as bases produtivas e comerciais, números de produtores, estabelecimentos, áreas cultivadas, sistemas de cultivos, valores de venda, entre outros, com particular envolvimento de órgãos como o IBGE, SEBRAE, CNA - Confederação Nacional da Agricultura, CNI - Confederação Nacional da Indústria e CNC - Confederação Nacional do Comércio, entre outros. Diretriz de Curto Prazo;

- Fortalecer o potencial de geração, captação, análise e divulgação das informações pertinentes a todos os setores e segmentos da Cadeia Produtiva, especialmente quanto aos mercados e suas oportunidades técnicas e comerciais, melhorando a qualidade na tomada de decisões, o nível de conhecimento técnico, a atualização permanente, o intercâmbio e a visibilidade da floricultura brasileira. Diretriz de Médio Prazo;

- Aumentar e fortalecer o intercâmbio e o envolvimento permanentes dos agentes regionais, suas associações e cooperativas com seus congêneres de outros Estados, ou de nível nacional e internacional, de modo a propiciar o crescimento profissional contínuo, maior potencial na coletivização de demandas e busca de soluções comuns. Diretriz de Médio Prazo;
- Incentivar a criação de associações, entidades e fóruns de representação, promoção e defesa de interesses em cada um dos elos específicos da Cadeia Produtiva, de modo a viabilizar e promover maior fortalecimento, representatividade e equilíbrio nas ações de coordenação e governança interna da floricultura de todo o Brasil. Diretriz de Longo Prazo;

- Combater sistemática e eficazmente a informalidade em todos os elos e segmentos da Cadeia Produtiva, de modo a garantir total transparência, o correto dimensionamento das características socioeconômicas da atividade no país, seu potencial de contribuição, bem como a justeza de suas demandas junto aos órgãos governamentais competentes de fiscalização, tributação, normalização e fomento. Diretriz de Longo Prazo.

\section{Ciência e Tecnologia}

- Incentivar o desenvolvimento de pesquisas científicas e tecnológicas especialmente vocacionadas e especializadas no atendimento da floricultura nas condições ecológicas e geoclimáticas dos principais pólos de produção do país, agregando ainda uma eficiente rede de assistência técnica e extensão rural, de âmbitos públicos e/ou privado, aos produtores e distribuidores. Diretriz de Longo Prazo;

- Incentivar e promover a pesquisa científica e tecnológica especialmente voltada para a criação, desenvolvimento e proteção de novos materiais genéticos, produtos e cultivares de interesse e potencial estratégicos para os negócios setoriais, especialmente aquelas baseadas em produtos originais da flora ou melhor adaptados às condições geo-ecológicas brasileiras. Diretriz de Longo Prazo;

- Evoluir para a criação e implementação de Sistemas de Certificação de Qualidade e de Origem para as flores e plantas ornamentais do Brasil, agregando valor, confiabilidade, visibilidade e referencial qualitativo nos mercados interno e externo. Diretriz de Médio Prazo;

- Desenvolver e implantar o Programa de Produção Integrada de Flores e Plantas Ornamentais do Brasil, incentivando a sua ampla, ágil e generalizada adoção pelos produtores, especialmente nos segmentos focados no crescimento das exportações, como forma de promover a adequação aos padrões básicos de exigências no mercado internacional. Diretriz de Médio Prazo;

- Promover o desenvolvimento e a alocação de recursos humanos especializados no atendimento das demandas locais, através de políticas de contratação coletivas de serviços, convênios e protocolos com universidades e centros de pesquisa e intercâmbios, entre outros mecanismos. Diretriz de Longo Prazo.

\section{Profissionalização, Qualificação e Capacitação de Recursos Humanos}

- Promover a capacitação para todos os elos componentes da Cadeia Produtiva, entendida como um processo permanente e cumulativo, inserido na realidade objetiva de cada grupo de produtores e outros agentes, nas áreas temáticas técnicoprodutivas, gerenciais e comerciais, utilizando-se de instrumentos como cursos, treinamentos, viagens, missões técnicas e outros afins. Diretriz de Curto Prazo; 
- Promover a formação de quadros profissionais de níveis superior e técnico, especialmente capacitados para o atendimento das demandas da Cadeia Produtiva de Flores e Plantas Ornamentais do Brasil, de modo a viabilizar um adequado atendimento, bem como a construção de uma verdadeira inteligência brasileira em floricultura, paisagismo e jardinagem. Diretriz de Longo Prazo;

- Promover a capacitação e a profissionalização do técnico em jardinagem. Diretriz de Médio Prazo;

- Participar e promover feiras, rodadas e encontros de negócios como modo comprovadamente eficiente de atualização, promoção e intercâmbio de informações, produtos e oportunidades comerciais em todos os segmentos afins. Diretriz de Curto Prazo;

- Estimular a busca pela constante atualização técnica e informação sobre as tendências contemporâneas dos mercados consumidores internacional, nacional, regionais e locais, especialmente no campo da arte floral, da decoração, do paisagismo e da jardinagem, como modo de impulsionar vendas, adequar produtos e processos e agregar valor aos produtos e serviços produzidos e oferecidos pela Cadeia Produtiva. Diretriz de Curto Prazo; - Incentivar a especialização profissional e a habilidade técnica e comercial de técnicos, gerentes e empresários dos diversos segmentos, dando especial ênfase a projetos e programas de educação continuada, estágios de intercâmbio, palestras e cursos motivacionais e de atualização tecnológica. Diretriz de Médio Prazo;

- Promover o treinamento, capacitação, intercâmbio e atualização tecnológica permanente de artistas e designers florais, especialmente no tocante ao uso de flores e folhagens tropicais em ornamentação e a sua promoção tanto no mercado interno, quanto internacional. Diretriz de Médio Prazo.

\section{Normas, Regulamentações e Políticas que afetam a Floricultura}

- Contribuir ativamente junto aos órgãos de representação setorial como o Ibraflor e a Câmara Setorial da Cadeia Produtiva de Flores e Plantas Ornamentais do Brasil, no sentido de agilizar, atualizar, adequar e rever todo o arcabouço legislativo e normativo políticoinstitucional que afeta o desenvolvimento e a operacionalização das atividades da floricultura brasileira, especialmente no que se refere à registro, extensão de uso e rotulagem de produtos agro-químicos, proteção fitossanitária, importação e exportação de insumos e materiais biológicos, registro e proteção de cultivares, tributação da atividade produtiva e comercial e simplificação dos processos e rotinas burocráticas e fiscais na implantação, operação e gestão de empresas e negócios, do comércio interno e da exportação. Diretriz de Curto Prazo;

- Promover, colaborar e incentivar a aprovação da Lei da Pequena Empresa no Brasil. Diretriz de Médio Prazo;

- Promover e orientar a regulamentação da profissão do paisagista no Brasil. Diretriz de Médio Prazo;

- Promover e orientar a elaboração e implementação de Planos Diretores de Arborização e Paisagismo Urbanos em todo o país, segundo as diferentes vocações, características e condições geo-climáticas e ecológicas de cada região. Diretriz de Longo Prazo.

\section{Créditos, Financiamentos e Seguros}

- Buscar a instituição e a criação de mecanismos adequados e eficientes de concessão de créditos e financiamentos para os diversos elos e segmentos da Cadeia Produtiva, especialmente no que se refere a investimentos na aquisição de máquinas agrícolas e veículos de carga, construções, ampliação e reforma de instalações para a produção, conservação, comércio atacadista e varejista, custeio e aquisição de insumos, entre outros. Diretriz de Médio Prazo;

- Estimular o conhecimento dos principais indicadores do funcionamento e desempenho da floricultura junto às entidades bancárias e creditícias, no sentido de aumentar a percepção, avaliação e aceitação da atividade no rol das culturas normalmente beneficiadas com o crédito, o financiamento e o seguro. Diretriz de Longo Prazo;

- Criar mecanismos de captação e concessão de créditos e financiamentos específicos para Programas de Certificação, Qualidade, Produção Integrada Padronização e Classificação de Produtos e Embalagens na Floricultura Brasileira. Diretriz de Longo Prazo.

\section{Gestão Empresarial}

- Organização de cadastros e disponibilização de informações sobre a idoneidade e histórico comercial de compradores e consumidores intermediários e finais, nos diversos segmentos, de modo a contribuir para a minimização de inadimplências e aumento das seguranças nas transações entre os agentes da Cadeia Produtiva. Diretriz de Médio Prazo;

- Busca de mecanismos e tecnologias atualizadas e adequadas de comercialização, com vistas à rápida adaptação à mudanças e novas exigências do mercado, incorporando gradativamente opções de comércio eletrônico, gestão informatizada de produtos e processos, entre outras que, além dos efeitos diretos e imediatos sobre os resultados econômicos e financeiros da comercialização, gerarão e distribuirão benefícios gerais ao longo da Cadeia Produtiva, especialmente no que se refere à padronização e classificação de produtos, embalagens e processos, conservação pós-colheita de produtos e regularização do abastecimento do mercado. Diretriz de Curto Prazo.

\section{Associativismo e Cooperativismo}

- Estímulo e fortalecimento do associativismo e do cooperativismo nos diversos segmentos componentes da Cadeia Produtiva, como mecanismo dos mais relevantes na defesa dos interesses setoriais e conquista de objetivos comuns. Diretriz de Médio Prazo;

• Estímulo à criação, implementação e gestão de consórcios e alternativas coletivas de comercialização, especialmente no campo das exportações, visando à superação dos gargalos identificados de agregação de cargas e grandes volumes para o comércio internacional, padronização de produtos e embalagens, aumento a competitividade da floricultura nacional. Diretriz de Longo Prazo.

\section{Infra-estrutura e Logística}

- Aumento da capacidade geral de investimento em todos os elos da Cadeia Produtiva que resultem no mais amplo e 
adequado aparelhamento da infra-estrutura produtiva e comercial, incluindo a instalação de estufas, packing houses, câmaras frias, depósitos e lojas de varejo melhor localizadas e capazes de realizar as reformas de layout e apresentação nos padrões estéticos e funcionais, com a freqüência que o consumidor exige. Diretriz de Médio Prazo;

- Criar e implantar os Corredores de Exportação de Flores e Plantas Ornamentais do Brasil, gerando fluxos tipo courrier, conferindo agilidade e prioridade no trânsito e despacho dos produtos mais perecíveis. Diretriz de Médio Prazo;

- Implantar linhas regulares de vôos e fretes cargueiros nos principais trechos ponto-aponto entre a origem e o destino das principais mercadorias exportadas. Diretriz de Longo Prazo;

- Despender esforços permanentes para a redução do Custo Brasil, especialmente no que se refere aos custos dos fretes aéreos, visando ao aumento da competitividade e agressividade das exportações nacionais. Diretriz de Médio Prazo;

- Implementar câmaras frias e ambientes climatizados especializados no setor de flores e plantas ornamentais junto aos principais aeroportos de embarque de mercadorias, em todo o país. Diretriz de Longo Prazo;

- Desenvolver programas de adequação e melhorias na infra-estrutura, equipamentos e no transporte fluvial e marítimo de cargas de perecíveis. Diretriz de Longo Prazo.

\section{Promoção no Mercado Internacional}

- Promoção de campanhas de apoio, divulgação e promoção dos produtos brasileiros nos principais mercados-alvo internacionais, especialmente nas grandes feiras e eventos de projeção setorial, com ênfase na criatividade, beleza e atualidade da arte floral do Brasil, como um dos principais instrumentos impulsionadores das vendas externas. Diretriz de Médio Prazo.

\section{Grupo Temático Responsável pela Elaboração do Documento}

\author{
Coordenação \\ - Renato Optiz \\ - Maria Mazarelo Boquadi
}

\section{Colaboração}

No Âmbito da Câmara Setorial da Cadeia Produtiva de Flores e Plantas Ornamentais:

- Instituto Brasileiro de Floricultura - IBRAFLOR

- Ministério da Agricultura, Pecuária e Abastecimento

- Associação Brasileira de Proteção de Cultivares de Flores e Plantas Ornamentais ABPCFlor

- Sociedade Brasileira de Floricultura e Plantas Ornamentais - Associação Nacional de Paisagismo - ANP

- Associação Nacional de Arquitetos Paisagistas - ANAP

- Associação Brasileira do Comércio de Sementes e Mudas -ABCSEM

- Associação Nacional de Defensivos e Fertilizantes - ANDEF

- Companhias de navegação e transportes terrestre, marítimo e aéreo
- Mercados Atacadistas e Centrais de Distribuição Privados ou Mistos

\section{No Âmbito do Setor Público e Institucional:}

- Ministério do Desenvolvimento, Indústria e Comércio Exterior

- Ministério da Fazenda / Secretaria da Receita Federal

- Ministério do Desenvolvimento Agrário

- Ministério da Ciência e Tecnologia

- Ministério do Meio Ambiente

- Serviço Brasileiro de Apoio às Micro e Pequenas Empresas-SEBRAE

- Confederação Nacional da Agricultura - CNA

- Confederação Nacional da Indústria - CNI

- Confederação Nacional do Comércio - CNC

- Confederação Nacional dos Transportes - CNT

- Serviço Social do Comércio - SESC

- Serviço Nacional de Aprendizagem Rural - SENAR

- Serviço Nacional de Aprendizagem Industrial - SENAI

- Organização das Cooperativas do Brasil - OCB

- Banco do Brasil S/A - BB

- Empresa Brasileira de Infra-estrutura Aeroportuária INFRAERO

- Universidades Federais

- Comissão Executiva do Plano da Lavoura Cacaueira CEPLAC

\section{Nos Âmbitos regional e estadual Privado:}

- Câmaras e Comitês Estaduais da Cadeia Produtiva de Flores e Plantas Ornamentais

- Associações e Cooperativas de Produtores

- Organizações das Cooperativas Estaduais

- Sindicatos Rurais

- Empresas organizadoras de feiras e eventos técnicos e comerciais

- Associações Estaduais e Regionais de Paisagistas Público e Institucional:

- Secretarias Estaduais e Municipais de Agricultura

- Secretarias Estaduais e Municipais de Desenvolvimento, Indústria e Comércio

- Secretarias Estaduais e Municipais de Ciência e Tecnologia

- Secretarias Estaduais da Fazenda/Receitas Estaduais

- Secretarias Estaduais e Municipais do Meio Ambiente

- SEBRAEs Estaduais

- Federações Estaduais de Agricultura

- Federações Estaduais da Indústria

- Federações Estaduais do Comércio

- SESCs Estaduais

- SENAIs Estaduais

- SENARs Estaduais

- Universidades Estaduais/Municipais

- CEASAs e outros mercados atacadistas

- Empresas Estaduais de Assistência Técnica e Extensão Rural-EMATER

\section{Entidades e Órgãos que Compõem a Câmara}

- Associação Brasileira de Proteção de Cultivares de Flores e Plantas Ornamentais-ABPCFLOR 
- Associação Brasiliense dos Produtores de Flores e Plantas - Central Flores Brasília

- Associação dos Produtores de Flores e Plantas Ornamentais de Atibaia - PROFLOR

- Associação dos Produtores de Flores Tropicais de Sergipe -SERGIFLORA

- Associação dos Produtores Rurais e Distribuidores de Flores e Plantas Ornamentais do Estado do Rio de Janeiro -AFRORG

- Associação Riograndense de Floriculturas - AFRORI

- Associação Nacional de Defesa Vegetal - ANDEF

- Banco do Brasil S/A - BB

- Comissão da Agricultura, Pecuária, Abastecimento e Desenvolvimento Rural da Câmara dos Deputados CAPADR

- Câmara Setorial de Flores e Plantas Ornamentais do Estado de São Paulo

- Centrais de Abastecimento do Paraná S/A - Mercado de Flores e Plantas Ornamentais

- Companhia de Entrepostos e Armazéns Gerais de São Paulo-CEAGESP

- Confederação da Agricultura e Pecuária do Brasil - CNA

- Cooperativa dos Produtores e Exportadores de Plantas,

Flores e Folhagens Tropicais de Alagoas - COMFLORA

- Cooperativa Veiling Holambra

- Empresa Brasileira de Infra-Estrutura Aeroportuária INFRAERO

- Empresa Brasileira de Pesquisa Agropecuária - Embrapa

- Instituto Agronômico de Campinas - IAC

- Instituto Brasileiro de Floricultura - IBRAFLOR

- Mercado das Flores e Plantas Ornamentais de Santa Catarina/Associação dos Produtores de Plantas Ornamentais de Santa Catarina - MERCAFLOR

- Ministério da Agricultura, Pecuária e Abastecimento MAPA

- Secretaria de Defesa Agropecuária - SDA

- Secretaria de Desenvolvimento Agropecuário e Cooperativismo - SDC

- Secretaria Executiva - SE

- Secretaria de Política Agrícola - SPA

- Superintendência Federal de Agricultura no Estado do

Rio Grande do Sul - SFA/RS

- Ministério do Desenvolvimento Agrário - MDA

- Ministério do Desenvolvimento, Indústria e Comércio

Exterior-MDIC

- Ministério do Meio Ambiente - MMA

- Ministério da Ciência e Tecnologia - MCT

- Ministério da Fazenda - MF

- Secretaria da Agricultura e Abastecimento do Estado de São Paulo - SAA/SP

- Serviço Brasileiro de Apoio às Micro e Pequenas Empresas - SEBRAE

- Sociedade Brasileira de Floricultura e Plantas Ornamentais

\section{Bibliografia Consultada}

ABIPTI. Agropolo como modelo de gestão para organização e inserção da agricultura familiar nas cadeias produtivas. Informe No 136, ano 24. Brasília-DF. abr.mai.2003.
AGÊNCIA CT. Município do agreste pernambucano terá Centro Vocacional Tecnológico de Floricultura. Disponível em: http://www.agencia.mct.gov.br. Acesso em: 04.mai.2006.

AGRIANUAL 2001. Anuário da Agricultura Brasileira. Artigos especiais: Valter Udler Cromberg, FNP: São Paulo. p.337-340.

AGRIANUAL 2002. Anuário da Agricultura Brasileira. Artigos especiais: Valter Udler Cromberg, FNP: Editora, p.353-354, 2002.

AGRONLINE. Disponível em: http://www.agronline.com. br/agronoticias/noticia.php?id=564 Acesso em 01.jun.2006.

AGROBRASIL. Balanço Brasileiro do Agronegócio. Ano 01. Nº1. p. 96-103. Dezembro, 2004.

ANEFALOS, Cristina Lílian \& GILHOTO, Joaquim J. M. Estrutura do Mercado Brasileiro de Flores e Plantas Ornamentais. Agric. São Paulo, SP, 50(2): 41-63, 2003.

BANCO CENTRAL DO BRASIL: Crédito Rural. Disponível em: http://www.bcb.br. Acesso em 03.jun.2006.

BANCO DO NORDESTE. O nosso negócio é desenvolvimento. Disponível em: www.bnb.gov.br. Acesso em: 03.jun.2006.

BRITISH Columbia. An Overview of the BC Floriculture Industry. FactSheet. Oct. 2003. Disponível em: http:// www.agf.gov.bc.ca/ornamentals/publications/ documents/overview floriculture 2003oct28.pdf Acesso em: 14.jun.2005.

CBI NEWS BULLETINS 2004, Disponível em: http:// www.cbi.nl/. Acesso em jan.2005.

DUTCH MINISTRY OF AGRICULTURE, NATURE AND FISHERIES. The dutch floriculture sector. Haia, Oct. 2000.

FLORABRASILIS. Relatório do diagnóstico da produção de flores e plantas ornamentais brasileiras (compact disc). Campinas: IBRAFLOR, 2002.

FLORANET. Análise Conjuntural das Exportações de flores e plantas ornamentais do Brasil. Disponível em: http//www.floranet.com.br Acesso em jun.2006.

FNPonline. Disponível em: http://www.fnp.com.br. Acesso em: mai.2005.

IBRAFLOR. Instituto Brasileiro de Floricultura. Relatório do Diagnóstico da Produção de Flores e Plantas Ornamentais Brasileira. São Paulo. IBRAFLOR. 2002. p.02.

IBRAFLOR. Plano estratégico para as exportações de flores e plantas ornamentais do Brasil - Relatório final. jan.2005.

INFORMATIVO SECEX. Panorama setorial: flores e plantas ornamentais. Brasília: Secretaria de comércio exterior - Secex - Ministério do Desenvolvimento, Indústria e Comércio exterior, ano V, n. 31, mar. 2002.

JORNAL DE PERNAMBUCO ONLINE. A terra das flores tropicais. Disponível em: http://www.pe.gov.br . Acesso em 03.jun.2006. 
JUNQUEIRA, Antonio Hélio e PEETZ, Macia da Silva Pesquisa Qualitativa sobre o Potencial Exportador de Flores e Plantas Ornamentais do Brasil.Programa FloraBrasilis (Ibraflor/APEX-Brasil), jun.2004, 60 p. (mimeo).

JUNQUEIRA, Antonio Hélio e PEETZ, Macia da Silva. Os pólos de produção de flores e plantas ornamentais do Brasil: uma análise do potencial exportador.

Revista Brasileira de Horticultura Ornamental. Campinas, São Paulo, 2002, v.8, n. ${ }^{0}$ 1/2:25-48.

KIYUNA, I. et al. Desempenho do Comércio Exterior Brasileiro de Produtos da Floricultura em 2003. Disponível em http://www.iea.sp.gov.br/out/ verTexto.php? codTexto=1228. São Paulo, 2004. Acesso em: 05.jul.2005.

et al. (a) Desempenho do Comércio Exterior Brasileiro de Produtos da Floricultura em 2004. Disponível em: http://www.iea.sp.gov.br São Paulo, 2005. Acesso em 05.jul.2005.

et al. (b) Floricultura: tendência crescente nas exportações. Disponível em: http://www.iea.sp.gov.br São Paulo, 2005. Acesso em 05.jul.2005.

et al. (c) Comércio exterior de produtos da floricultura em 2004: desempenho e oportunidades. In: CONGRESSO BRASILEIRO DE ECONOMIA E SOCIOLOGIA RURAL, 43, Ribeirão Preto, 2005. Anais... Ribeirão Preto: SOBER, 2005. CD.

KRAS, J. Marketing of cut flowers in the future. Acta Horticulturae, n.482, p.401-405, Mar. 1999. (Apresentado ao International Symposium of Cut Flowers in the Tropics, Bogota, 1998).

LAWS, Nancy. 2003: a strong year for floriculture. FloraCulture International, Batavia, v.15, n.2, p.26-29, 2005.

LIMA, C. Ricardo. Perfis Econômicos e Construção de Cenários de Desenvolvimento Para o Estado de Pernambuco, com Ênfase na Mesorregião da Zona da Mata: Perfil Econômico e Cenários de Desenvolvimento para a Cadeia Produtiva de Floricultura, (mimeo) Recife, jul-2005. 60 p.

MEDEIROS, F. O. Estudo da Cadeia Produtiva de Flores Temperadas no Município de Gravatá, Estado de Pernambuco: segmento - Produção e Distribuição no Atacado. Monografia de conclusão do curso de Economia Rural da UFRPE. Recife, 2005.

MINISTÉRIO DO PLANEJAMENTO, ORÇAMENTO E GESTÃO. Mapeamento das Ações Orçamentárias Integrantes da Proposta Orçamentária para 2003.

MOTOS J. R., PACHECO M. M. Mercado internacional de flor y verdes de corte.
Revista Horticultura. No 181. dez.2004.

MOTOS, J.R.; NOGUEIRA JUNIOR., S. P. Flora Brasilis. Agroanalysis, v.21, n.8, p.39- 40, ago.2001.

MOTOS, J.R.; SABUGOSA, Eduardo. Atualização das informações sobre Mercado Internacional de Flores e Plantas Ornamentais. Programa FloraBrasilis (Ibraflor/ APEX-Brasil), jun.2004, (mimeo).

OPITZ, R. As Perspectivas para o Mercado Mundial de Flores Tropicais. In: $12^{\mathrm{a}}$ Semana Internacional da Fruticultura, Floricultura e. Agroindústria - FRUTAL 2005, Fortaleza.

PERTWEE, J. The International Cut Flower Data Base. Netherlands. 2004.

REVISTADE POLÍTICAAGRÍCOLA on line. Ano XIII- No 2 - abr.mai.jun.2004. Acesso em: mai.2006.

SAITO, T. - "Logística de flores” - Trabalho apresentado na Florinvest, 2001.

SEBRAE. Jardim de oportunidades. Revista SEBRAE de Agronegócios. Nº1. set. 2005.

SEBRAE (a). Revista Agronegócios. Avanços Científicos e tecnológicos impulsionam o desenvolvimento da floricultura brasileira. Disponível em: http:// www.sebrae.com.br. Acesso em: 29.mai.2006.

SEBRAE (b). Revista Agronegócios. Flores que realizam sonhos. Disponível em: http://www.sebrae.com.br Acesso em 29.mai.2006.

SEBRAE-PE. Floricultura em Pernambuco. Recife, 2002. (Série Agronegócio).

Projeto Setorial Integrado de Promoção das Exportações de Flores e Folhagens de Corte de Pernambuco - PSI. Recife, 2003.

SECOM-Boletim de Mercado: O Mercado de Flores Frescas e de Flores Secas no Japão - Tóquio 1 / 9. Elaborado em mar.2004.

UNCTAD in: Sub-Regional Workshop on Environmental requirements, market access/entry and export competitiveness in the Horticultural Sector. Bangkok, 29 September - 1 October 2004. International Institute for Trade and Development (ITD).

VERDES MARES. Pesquisa científica na floricultura será debatida no VIII.

Agroflores. Disponível em: www.verdesmares.globo.com. Acesso em: 30.mai.2006.

XAVIER, P. F. M.; FAVERO, L. A. A competitividade da Cadeia Exportador de Flores Tropicais de Pernambuco. In: CONGRESSO BRASILEIRO DE ECONOMIA E SOCIOLOGIA RURAL, 43, Ribeirão Preto, 2005. Anais... Ribeirão Preto: SOBER, 2005. CD. 